\title{
Transcatheter Coil Embolization of latrogenic Aorto-Right Atrial Fistula
}

\author{
Muhammad Umer Awan ${ }^{\mathrm{a}}$, Kulwant Bath ${ }^{\mathrm{a}}$, Nilarun Chowdhuria , Siva Chiranjeevia, \\ Mashal Mumtaz ${ }^{\mathrm{b}}$, Hassan Tahira, d, Bassam Omar ${ }^{\mathrm{a}}$, Jason Cole ${ }^{\mathrm{a}, \mathrm{c}}$
}

\begin{abstract}
Coronary artery fistula (CAF) is a rare complication following coronary artery bypass grafting (CABG). True incidence is unknown, as at least $50 \%$ are asymptomatic. CAF can be either congenital or acquired. Congenital CAF is either an isolated finding or seen with other congenital cardiac anomalies or structural heart defects. Acquired $\mathrm{CAF}$ is seen in relation with trauma, infection, or iatrogenic injury. We report a rare case of a 58-year-old man with iatrogenic aorto-right atrial fistula following inadvertent saphenous vein grafting (SVG) implantation to a right coronary vein with persistent angina following $\mathrm{CABG}$ and resolution of symptoms following successful obliteration of large, hemodynamically significant, fistulae by coil embolization when medical management failed.
\end{abstract}

Keywords: Coronary artery fistula; Coil embolization; SVG; CABG; Aorto-right atrial fistula

\section{Introduction}

We report a rare case of symptomatic aorto-right atrial fistula created by a saphenous vein graft (SVG) inadvertently anastomosed to a coronary vein, treated successfully with catheterbased coiling.

\section{Case Report}

A 58-year-old man was referred to our facility with complaints of progressive worsening shortness of breath along with decreased functional capacity and fatigue. Past medical history included hypertension, hyperlipidemia, gastroesophageal reflux disease, and non-ST segment elevation myocardial infarction 1 year ago

Manuscript submitted March 3, 2020, accepted March 23, 2020

${ }^{a}$ University of South Alabama, Mobile, AL, USA

bUniversity College of Medicine and Dentistry, Lahore, Pakistan

${ }^{\mathrm{c} C a r d i o l o g y}$ Associate-Spring Hill Medical Center, Mobile, AL, USA

${ }^{\mathrm{d} C}$ Corresponding Author: Hassan Tahir, University of South Alabama, USA Medical Center Drive, 2451 Fillingim Street, Suite 10B, Mobile, AL 36617, USA. Email: HTahir@health.southalabama.edu

doi: https://doi.org/10.14740/jmc3448 requiring coronary artery bypass grafting $(\mathrm{CABG})$ with lateral internal mammary artery (LIMA) to left anterior descending artery (LAD), SVG to first diagonal, ramus intermedius (RI) and right coronary artery (RCA). After surgery, patient started complaining of above-mentioned symptoms and was initially treated with up-titration of antianginal therapy without relief of his symptoms. Patient was admitted to our facility with unstable angina. Physical examination was unremarkable. A 12-lead electrocardiogram showed normal sinus rhythm and no acute ST segment abnormalities concerning for ischemia. Transthoracic echocardiogram showed normal right and left ventricular size and function, grade I diastolic dysfunction and mild tricuspid regurgitation. Right heart catheterization showed significant stepup of oxygen saturation from inferior vena cava and underwent right and left heart catheterization which showed native threevessel atherosclerotic coronary artery disease including 99\% mid LAD, 30\% proximal circumflex, and $100 \%$ proximal RI. There is $50 \%$ to $60 \%$ diffuse RCA disease (Fig. 1). Fractional flow reserve (FFR) was performed for RCA diffuse disease, and measured FFR was 0.88 , which was hemodynamically non-significant. LIMA to LAD, and SVGs to D1 and RI were patent. SVG destined to RCA was anastomosed to an anomalous right coronary vein which drained into right atrium (Fig. 2). Coronary computed tomography showed patent SVG to small right coronary vein with flow distal into the right atrium (Fig. 3). The RCA coursed immediately subjacent to the right coronary vein, though the graft did not anastomose to the RCA. Patent SVG to RI and diagonal branches was observed. Approximately $50 \%$ focal luminal narrowing of the RCA was immediately subjacent to the aforementioned anomalous vein as above. Luminal reconstitution was appreciated distal to this stenotic segment. A multidisciplinary "Heart Team" meeting was convened and it was decided to proceed with catheter-based coiling. Coil embolization of the SVG to right coronary vein was performed. Using a Prowater coronary wire, the guide catheter was placed in the proximal and mid segments of the graft and a Direxion $0.021 \times 130 \mathrm{~cm} \mathrm{mi-}$ crocatheter was placed in mid segment of graft. Five diamondshaped interlock-18 coils (Boston Scientific) were implanted to occlude the shunt. A subsequent angiogram revealed complete obliteration of iatrogenic aorto-right atrial shunt (Fig. 4). The patient's symptoms significantly improved upon follow-up.

\section{Discussion}

Coronary artery fistula (CAF) is an abnormal connection be- 


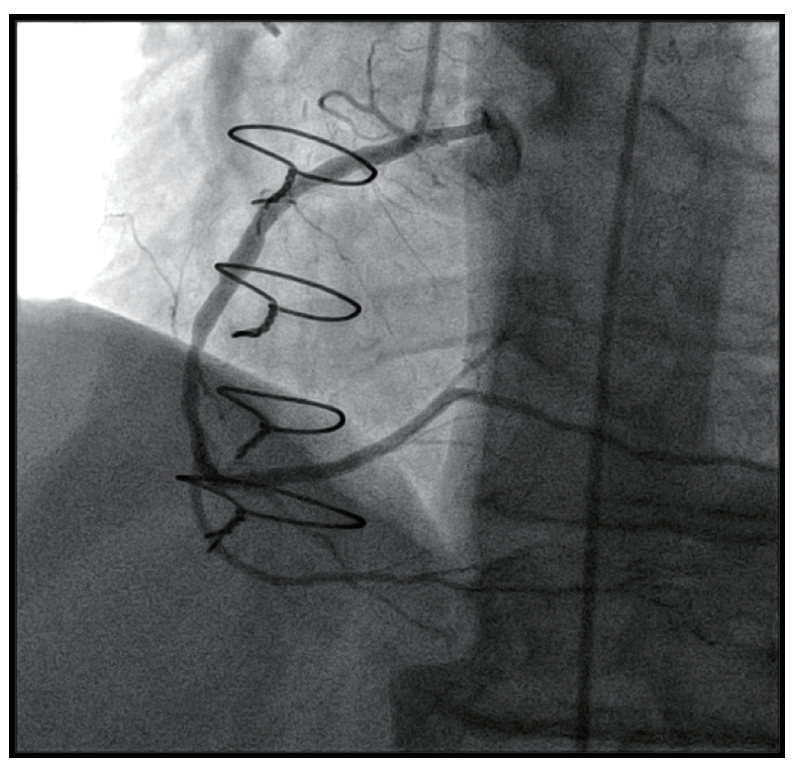

Figure 1. LAO cranial view showing right coronary artery dividing into PDA and PLV branches. LAO: left anterior oblique; PDA: posterior descending artery; PLV: posterior left ventricular.

tween a coronary artery and any of the four chambers of the heart, or any the great vessels (superior vena cava (SVC), pulmonary artery (PA), pulmonary vein (PV), and coronary sinus (CS)). Fistulas that arise from a coronary artery and terminate into a chamber of heart are known as coronary-cameral fistulas. Fistulas that terminate into vein are coronary arteriovenous fistulas (CAVFs). True incidence is unknown, as at least 50\% are asymptomatic. CAF accounts for $0.002 \%$ of the general population. They account for $0.2-0.4 \%$ of congenital cardiac anomalies. CAF can be either congenital or acquired. Congenital CAF is either an isolated finding or seen with other congenital car-

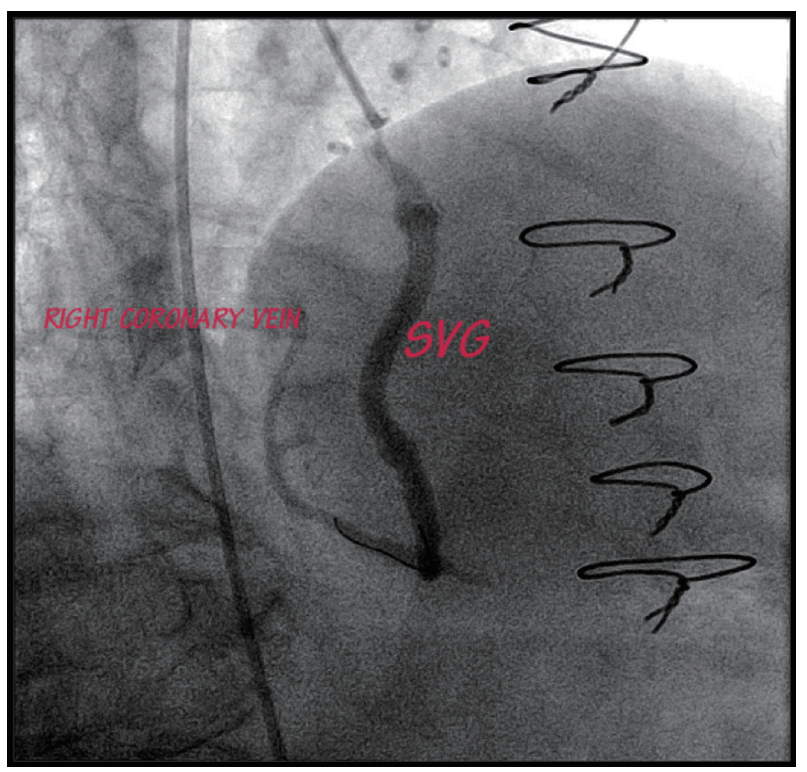

Figure 2. LAO caudal view after coil embolization of the iatrogenic aorto-right atrial shunt. LAO: left anterior oblique.

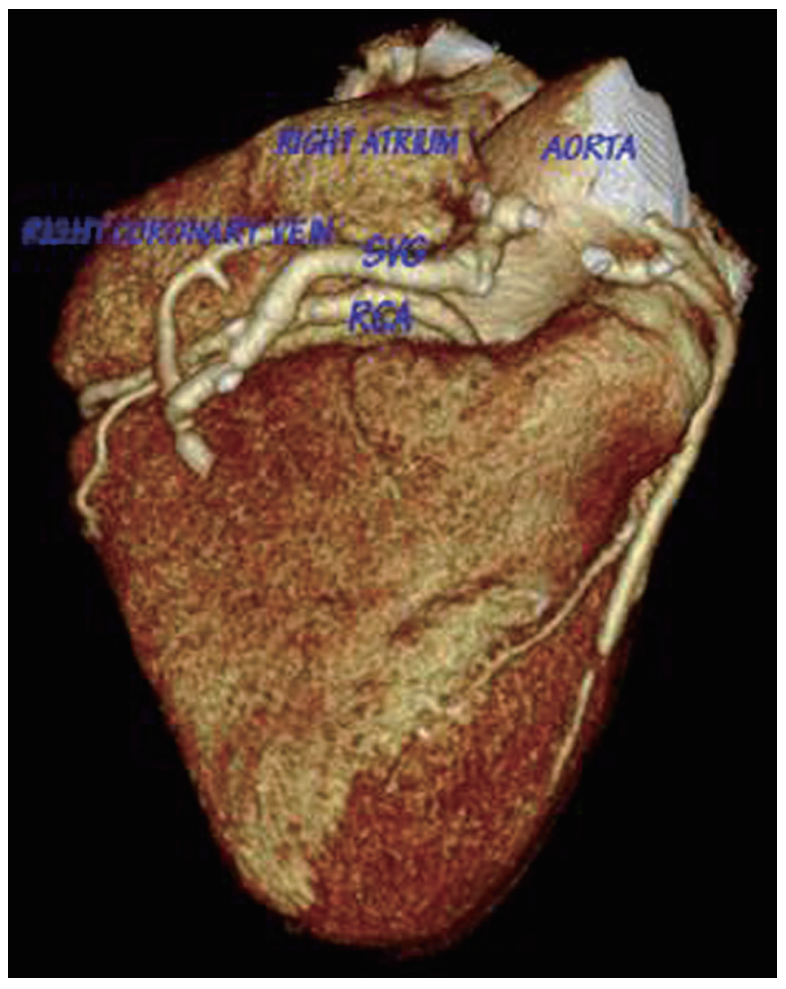

Figure 3. The 3D coronary CT imaging showing saphenous vein graft to right coronary vein draining into the right atrium. CT: computed tomography; 3D: three-dimensional.

diac anomalies or structural heart defects, most frequently in critical pulmonary stenosis or atresia, pulmonary artery branch stenosis, tetralogy of Fallot (TOF), coarctation of aorta, hypoplastic left heart syndrome and aortic atresia. Acquired CAF is seen in relation with trauma, infection, or iatrogenic injury,

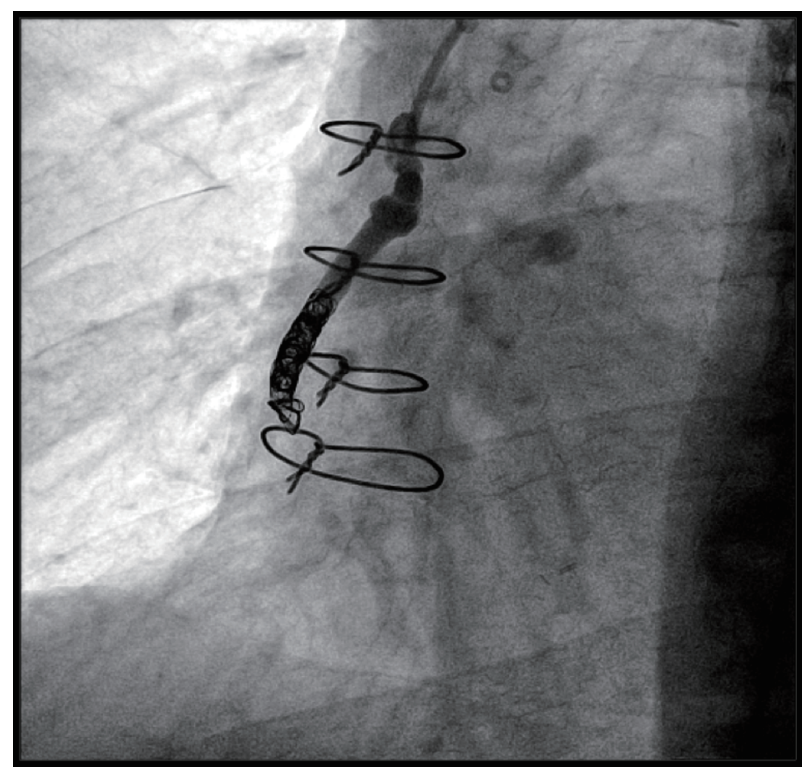

Figure 4. LAO caudal view after coil embolization of the iatrogenic aorto-right atrial shunt. LAO: left anterior oblique. 
such as an intracardiac congenital heart operation, transcatheter techniques, myocardial biopsy, CABG, septal myomectomies, permanent pacemaker (PPM) implantations, electrophysiology (EP) ablations, and transbronchial lung biopsies. Iatrogenic aortocoronary arteriovenous fistula (ACAVF) resulting from placement of an arterial or venous graft to a cardiac vein is a rare complication of CABG $[1,2]$. Only 37 such cases have been reported in literature. The reasons for this complication may be anatomical distortion due to myocardial scarring, intramyocardial course of intended artery, pericardial fibrosis, or previous coronary bypass surgery. Also, pericardial fat may disturb coronary exploration $[3,4]$. This iatrogenic CAVF may result in myocardial ischemia, infective endocarditis, severe systemic to pulmonary shunt, heart failure with high cardiac output, or fistula rupture [5]. Treatment options for iatrogenic CAF that have been reported in literature include either redo CABG, balloon or coil embolization, stenting of engrafted artery, or covered stent implantation in the cardiac vein [6-8]. Percutaneous closure by embolization with either detachable balloons or coils [9] or deployment of a vascular plug offers an effective and safe management for symptomatic patients.

\section{Conclusions}

We presented a rare case of iatrogenic aorto-right atrial fistula following inadvertent SVG implantation to a right coronary vein in a patient with persistent angina following CABG. Our case highlights the following main points. First, it emphasizes the serious clinical and cardiovascular ramifications of iatrogenic cardiac fistulae, and the need for vigilance and increased recognition of such potential complications on behalf of operators during any coronary revascularization procedure. Second, it demonstrates the feasibility and safety of coil embolization of cardiac fistulae by experienced operators in carefully selected cases with suitable anatomy. Third, it demonstrates the use of multimodality imaging especially coronary CT angiogram in confirming the diagnosis of coronary fistula and outlining the path of arteriovenous fistula. Lastly, it shows that marked symptomatic improvement can be achieved following successful obliteration of a large, hemodynamically significant, fistula when medical management has failed.

\section{Acknowledgments}

None to declare.

\section{Financial Disclosure}

None to declare.

\section{Conflict of Interest}

None to declare.

\section{Informed Consent}

Informed consent was taken from the patient.

\section{Author Contributions}

All authors sufficiently contributed to the intellectual content, review of literature and analysis of data. Each author has reviewed the final version of the manuscript and approves it for publication.

\section{Data Availability}

The authors declare that data supporting the findings of this study are available within the article.

\section{References}

1. Seabra-Gomes R, Ross DN, Gonzalez-Lavin L. Iatrogenic left ventricular - right atrial fistula following mitral valve replacement. Thorax. 1973;28(2):235-241.

2. Renard VP, Vandenbogaerde J. Fistula between the left internal thoracic artery and the coronary sinus. N Engl J Med. 2000;343(2):149-150.

3. Starling MR, Groves BM, Frost D, Toon R, Arom KV. Aorto-coronary vein fistula. A complication of coronary artery bypass graft surgery. Chest. 1981;79(1):64-68.

4. Treistman B, Sulbaran TA, Cooley DA. Saphenous vein bypass from the aorta to the anterior interventricular vein. Ann Thorac Surg. 1978;26(4):383-386.

5. Scholz KH, Wiegand V, Rosemeyer P, Chemnitius JM, Kreuzer H. Aorto-coronary artery to coronary vein fistula with the potential of coronary steal as complication of saphenous vein jump bypass graft. Eur J Cardiothorac Surg. 1993;7(8):441-442.

6. Gardner JD, Maddox WR, Calkins JB, Jr. Iatrogenic aortocoronary arteriovenous fistula following coronary artery bypass surgery: a case report and complete review of the literature. Case Rep Cardiol. 2012;2012:652086.

7. Thomas WJ, Moskowitz WB, Freedman A, Vetrovec GW, Goudreau E. Therapeutic embolization for unusual latrogenic complications related to coronary revascularization. Catheter Cardiovasc Interv. 1999;46(4):457462.

8. Lawrie GM, Morris GC, Jr., Winters WL. Aortocoronary saphenous vein autograft accidentally attached to a coronary vein: follow-up angiography and surgical correction of the resultant arteriovenous fistula. Ann Thorac Surg. 1976;22(1):87-90.

9. White RW, Sivananthan MU, Kay PH. Aortocoronary bypass graft fistula after surgical treatment of circumflex coronary artery fistula: a unique variation of a rare condition successfully treated with percutaneous embolization. Interact Cardiovasc Thorac Surg. 2010;10(2):256-257. 